\title{
THE SIGNIFICANCE OF ERRORS OF REFRACTION IN CHRONIC BLEPHARITIS OF CHILDREN*
}

\author{
BY \\ E. J. SOMERSET \\ LONDON
}

THE purpose of this paper is to enquire into the significance of refractive errors as an aetiological factor in children suffering from chronic blepharitis or blepharo-conjunctivitis. Permission was obtained from the London County Council to use the ample material at White Oak Hospital, Swanley, Kent, a hospital devoted to the treatment of chronic eye diseases of children. The patients come from all parts of the metropolis and are typical of a large urban population. All the children have been referred to Swanley from hospitals and clinics in London and elsewhere after undergoing treatment generally for a long period of time. Thus they are cases which have not responded to out-patient treatment. In many instances correct glasses had been prescribed at the hospital or clinic without materially affecting the course of the disease.

In 1894 Ernest Clarke ${ }^{1}$ investigated one hundred cases of blepharitis whose average age was seventeen years and included forty-four school children. Atropine was used for all cases under twenty and homatropine and cocaine for the remainder. Of the two hundred eyes examined his findings were as follows :

\begin{tabular}{|c|c|c|}
\hline Hypermetropia & $\ldots$ & \\
\hline Hypermetropic astign & ratism & \\
\hline Mixed astigmatism & $\ldots$ & $\ldots$ \\
\hline Myopia $\quad \ldots$ & $\ldots$ & $\ldots$ \\
\hline Myopic astigmatism & $\ldots$ & $\ldots$ \\
\hline Emmetropia $\quad \ldots$ & $\ldots$ & ... \\
\hline
\end{tabular}

He concluded that asthenupia due to ametropia was invariably present and although there was an underlying tendency to eczema or struma, the important factor in treatment was the ordering of glasses to correct the ametropia which he defined as :-

Astigmatism of more than $0.25 \mathrm{D}$., myopia and hypermetropia of more than $1.0 \mathrm{D}$.

There are few today who would agree that the normal refraction of the atropinized eye of a child is $+1.0 \mathrm{D}$. It has been shown ${ }^{2}$ \footnotetext{
1937 .

* Investigation carried out whilst holding the Royal Eye Hospital Scholarship for
} 
that the refraction of the new-born baby is about $+4 \cdot 0 \mathrm{D}$ (atropine); as the child grows older the hypermetropia diminishes. Sorsby ${ }^{3}$ has shown in a series of 672 unselected children at council infant schools that for children between the ages of 4 and 8 years the most common findings were from +1.50 to $+3.50 \mathrm{D}$. (atropine) of hypermetropia. The maximum incidence was at $+2 \cdot 50 \mathrm{D}$.

A large series of 2,625 unselected children is reported on in the Report of the Committee of Inquiry into Problems connected with Defective Vision in School Children. ${ }^{4}$ The findings cannot be considered conclusive for the following reasons :-

(1) Homatropine and cocaine only were used.

(2) There were twenty different refractionists.

(3) The highest myopic axis determined the group in myopia yet the highest hypermetropic axis determined the hypermetropic group.

Sorsby's cases are more satisfactory as they were all examined under complete atropine cycloplegia and by one observer.

In J. Hamilton McIlroy's ${ }^{5}$ results on 1,335 children from age 7 to 13 years no cycloplegic was used.

\section{Analysis of Findings in 300 cases at White Oak Hospital}

Retinoscopy, confirmed where possible by subjective tests, was performed under atropine cycloplegia achieved by instilling atropine ointment 1 per cent. for three days.

In tabulating the results, the computed refractive error (atropine) and not the neutralising lens which might have been ordered was considered and the axis of least hypermetropia or greatest myopia was used to determine into which group any particular case was to be placed; in mixed astigmatism the myopic axis was the determinant. The eye with the less hypermetropia is the determining eye. It will be seen from Table I that the groups are recorded as $-0.5,+0.5$, +1.5 , +2.5 , etc. The +0.50 group consists of cases from +0.25 to +1.0 inclusive, the -0.50 group 0 to -0.75 and the +2.50 group cases from $2 \cdot 25$ to $3 \cdot 0$, etc. The incidence of astigmatism was considered separately.

(1) Spherical Error.-Table I shows the incidence of refraction in 300 children between the ages of 2 and 13 years. The sexes were nearly equal there being 159 boys and 141 girls. It will be seen that the +1.50 group represents the numerically greatest and that 75 per cent. of the cases fall into the groups from +0.5 to +3.5 .

Table II is computed from the figures given in the Report of the Committee into Problems connected with Defective Vision. ${ }^{4}$ Though not strictly comparable, it is of interest to note that groups 
+0.5 to +3.5 in Table I approximately correspond to group $+1^{\circ} 0$ to +4.0 in Table II. $(75.4$ per cent. Table I and 81.1 per cent. Table II.

TABLE I

Blepharitis. Spherical error. 300 children. Age 2-13.

\begin{tabular}{|c|c|c|c|}
\hline Refraction & No. & Per cent. & \\
\hline$+9 \cdot 5$ & 2 & $0 \cdot 7$ & \\
\hline+8.5 & 1 & $0 \cdot 3$ & \\
\hline$+7 \cdot 5$ & 0 & - & \\
\hline+6.5 & 1 & $0 \cdot 3$ & \\
\hline$+5 \cdot 5$ & 9 & $3 \cdot 0$ & \\
\hline$+4 \cdot 5$ & 14 & $4 \cdot 7$ & \\
\hline+3.5 & 23 & $7 \cdot 7$ & \\
\hline$+2 \cdot 5$ & 52 & $17 \cdot 3$ & \\
\hline$+1 \cdot 5$ & 98 & $32 \cdot 7$ & $=75.4$ per cent. \\
\hline+0.5 & 53 & $17 \cdot 7$ & \\
\hline-0.5 & 32 & $10 \cdot 7$ & \\
\hline$-1 \cdot 5$ & 4 & $1 \cdot 3$ & \\
\hline$-2 \cdot 5$ & 1 & $0 \cdot 3$ & \\
\hline$-3 \cdot 5$ & 1 & $0 \cdot 3$ & \\
\hline$-4 \cdot 5$ & 5 & $1 \cdot 7$ & \\
\hline$-5 \cdot 5$ & 2 & 0.7 & \\
\hline$-6 \cdot 5$ & 1 & $0 \cdot 3$ & \\
\hline \multirow[t]{2}{*}{$-7 \cdot 5$} & 1 & $0 \cdot 3$ & \\
\hline & 300 & $100 \cdot 3$ & \\
\hline
\end{tabular}

Table III shows the figures found in the blepharitis series between the ages of 4 and 8 years, and Table IV the figures published by Sorsby of a similar age group of unselected school children. These show a similar grouping of cases round the +1.50 and +2.50 groups although the peak appears at +1.50 in the blepharitis cases and at +2.5 in Table IV.

(2) Astigmatism. - In recording astigmatism the method used by Sorsby has been followed. 0.25 and 0.50 have been omitted and the remainder classified as three groups, 0.75 and $1.0 ; 1.25$ to 2.0 ; and $2 \cdot 25$ and over. The eye showing the less astigmatism determines the group. 
TABLE $I^{4}$

Normal. Spherical error. 2,625 children. 3-13 years.

\begin{tabular}{|c|c|c|}
\hline Refraction & Per cent. & \\
\hline - & - & \\
\hline - & - & \\
\hline - & - & \\
\hline$+5 \cdot 0$ & $4 \cdot 7$ & \\
\hline$+4 \cdot 0$ & $6 \cdot 6$ & \\
\hline+3.0 & $22 \cdot 9$ & $=81.1$ per cent. \\
\hline$+2 \cdot 0$ & $30 \cdot 0$ & \\
\hline$+1 \cdot 0$ & $21 \cdot 6$ & \\
\hline 0 & $5 \cdot 2$ & \\
\hline$-1 \cdot 0$ & $2 \cdot 4$ & \\
\hline - & - & \\
\hline - & - & \\
\hline
\end{tabular}

TABLE III

Blepharitis. Spherical error. 149 children. $4-8$ years.

\begin{tabular}{|c|c|c|}
\hline Refraction & No. & Per cent. \\
\hline$+9 \cdot 5$ & 2 & $1 \cdot 3$ \\
\hline$+8 \cdot 5$ & 1 & $0 \cdot 6$ \\
\hline$+7 \cdot 5$ & 0 & - \\
\hline$+6 \cdot 5$ & 1 & 0.6 \\
\hline$+5 \cdot 5$ & 3 & $2 \cdot 0$ \\
\hline$+4 \cdot 5$ & 12 & $8 \cdot 0$ \\
\hline+3.5 & 15 & $10 \cdot 0$ \\
\hline$+2 \cdot 5$ & 32 & $21 \cdot 5$ \\
\hline$+1 \cdot 5$ & 38 & $25 \cdot 5$ \\
\hline+0.5 & 23 & $15 \cdot 4$ \\
\hline-0.5 & 17 & $11 \cdot 4$ \\
\hline$-1 \cdot 5$ & 1 & 0.6 \\
\hline$-2 \cdot 5$ & 1 & 0.6 \\
\hline$-3 \cdot 5$ & 0 & - \\
\hline$-4 \cdot 5$ & 3 & $2 \cdot 0$ \\
\hline \multirow[t]{2}{*}{$-5 \cdot 5$} & - & - \\
\hline & 149 & $99 \cdot 5$ \\
\hline
\end{tabular}


Chronic Blepharitis of ChildReN

TABLE IV

Normal. 672 children. Age $4-8$ years (Sorsby).

\begin{tabular}{c|c}
\hline Refraction & Per cent. \\
\hline+8.5 & 0.03 \\
+7.5 & 0.09 \\
+6.5 & 0.3 \\
+5.5 & 1.0 \\
+4.5 & 3.7 \\
+3.5 & 15.3 \\
+2.5 & 38.0 \\
+1.5 & 28.0 \\
+0.5 & 9.0 \\
-0.5 & 2.0 \\
-1.5 & 0.7 \\
-2.5 & 0.24 \\
-3.5 & 0.15 \\
-4.5 & 0.04 \\
-5.5 & 0.02 \\
\hline
\end{tabular}

TABLE V

Astigmatism. Blepharitis cases $3--13$ years. 300 children.

\begin{tabular}{|c|c|c|c|c|}
\hline \multicolumn{3}{|c|}{ A stigmatism } & \multirow{2}{*}{$\frac{\text { No. }}{23}$} & \multirow{2}{*}{ Per cent. } \\
\hline 0.75 to 1.0 & - & - & & \\
\hline 1.25 to 2.0 & - & - & 25 & $8 \cdot 3$ \\
\hline $2 \cdot 25$ and over & - & - & 15 & $5 \cdot 0$ \\
\hline \multicolumn{2}{|c|}{ Total } & - & 63 & $21 \cdot 0$ \\
\hline
\end{tabular}

TABLE VI

Astigmatism. Blepharitis cases $4-8$ years. 149 children.

\begin{tabular}{|c|c|c|c|}
\hline Astigmatism & & No. & Per cent \\
\hline 0.75 to 1.0 & - & 8 & $5 \cdot 3$ \\
\hline $1 \cdot 25$ to $2 \cdot 0$ & - & 17 & $11 \cdot 4$ \\
\hline $2 \cdot 25$ and over & - & 7 & $4 \cdot 7$ \\
\hline Total & - & 32 & $21 \cdot 4$ \\
\hline
\end{tabular}


Table $\mathrm{V}$ shows the incidence of astigmatism at all ages from 3 to 13 and Table VI records it in those children between 4 and 8 years.

Table VII is that recorded by Sorsby. The percentage of children with astigmatism (21 per cent. approximately) is strikingly similar $\left(21^{\circ} 4\right.$ per cent. and 20 per cent. respectively).

\section{TABLE VII}

Astigmatism in 672 normal children $4-8$ years (Sorsby).

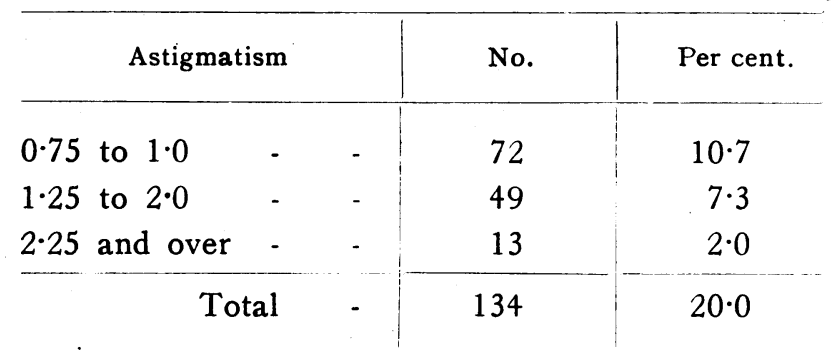

There is, however, a suggestion that astigmatism of over $1.0 \mathrm{D}$. is more frequent in the blepharitis cases, but no definite conclusion can be drawn on this small series.

(3) Uniocular cases.-There were among the 300 children 23 cases of uniocular blepharitis, and these have been divided into three groups.

(i) Equal refraction in either eye 8 cases as follows :-

$$
+0 \cdot 75,+1 \cdot 0, \frac{+1 \cdot 0}{+0 \cdot 25},+2 \cdot 0,+2 \cdot 0,+2 \cdot 5,+3 \cdot 5,+5 \cdot 5 \text {. }
$$

(ii) Cases of dissimilar refraction but not showing a difference of more than $0.5 \mathrm{D}$. between the two eyes and not possessing more than $0.25 \mathrm{D}$. of astigmatism. 7 cases.

\begin{tabular}{l|l|l|l}
\hline & Right & Left & Eye affected \\
\hline 1 & +0.50 & +0.75 & $\mathrm{~L}$ \\
2 & $+\frac{+0.50}{+0.25}$ & +0.50 & $\mathrm{~L}$ \\
3 & +2.0 & & \\
4 & $+0.25 \rightarrow$ & +2.0 & $\mathrm{~L}$ \\
5 & +2.50 & +2.0 & $\mathrm{R}$ \\
6 & +2.50 & +2.75 & $\mathrm{~L}$ \\
7 & +3.50 & +3.0 & $\mathrm{R}$ \\
\hline
\end{tabular}


(iii) Dissimilar refractions 8 cases. Five show a greater error in the eye with blepharitis and three in the more normal eye.

\begin{tabular}{l|l|l|l}
\hline & Right & Left & Eye effected \\
\hline 1 & $\frac{-0.25}{-3.25} \rightarrow$ & $\frac{+1.0}{+1.50}$ & $\mathrm{R}$ \\
2 & $\frac{0}{+3.50} \downarrow_{110}$ & $\frac{+0.50}{+3.50 \downarrow}$ & $\mathrm{R}$ \\
& -4.50 & $\frac{-2.25}{-0.25 \downarrow}$ & $\mathrm{R}$ \\
3 & +5.50 & +4.50 & $\mathrm{R}$ \\
4 & +4.0 & +4.50 & $\mathrm{~L}$ \\
5 & $\frac{0}{-3.50} \downarrow$ & +0.50 & $\mathrm{~L}$ \\
6 & $\frac{+4.0}{+0.50 \downarrow}$ & +2.0 & \\
7 & +11.75 & +9.25 & $\mathrm{~L}$ \\
\hline
\end{tabular}

Thus of the 23 cases of uniocular blepharitis 15 do not show any marked dissimilarity in the two eyes. Furthermore 14 cases show either equal refraction in either eye or the affected eye is the more normal ; only 9 show blepharitis in the eye with the greater error.

Summary. From a study of the refractive errors seen in 300 children aged $2-13$ years suftering from blepharitis it is concluded that :-

(1) There is no significant difference in the spherical refractive error in children suffering from blepharitis in comparison with the normal child.

(2) The incidence of astigmatism is similar in blepharitis cases and normal children.

(3) Uniocular cases do not show blepharitis more frequently in the eye with the greater ametropia.

(4) Causes other than errors of refraction must be sought for in blepharitis of children.

My thanks are due to the Royal Eye Hospital for their grant of the Royal Eye Hospital Research Scholarship for 1937, to the 
Special Hospitals Division of the London County Council and to Mr. Arnold Sorsby for his help and encouragement.

\title{
REFERENCES
}

1. Clarke, E.-Ophthal. Rev., Vol. XIII, p. 345, London, 1894.

2. Sorsby, A.-Brit. Med. Jl., Vol. II, p. 730, 1933.

3. Sorsby, A.-London County Council, Annual Report for 1935, Vol. IV, iii, p. 55.

4. Defective Vision in School Children, Report of the Committee of Enquiry. Great Britain Board of Education. His Majesty's Stationery Office, 1931.

5. McIlroy, J. H.-London County Council Annual Report, Vol. III, p. 86, 1928.

\section{A "PIN" EYE-DROPPER}

BY

\section{N. BISHOP HARMAN}

LONDON

OILY preparations of alkaloids for the treatment of eye diseases are in many cases preferable to watery solutions. Oily preparations keep better and, in some cases, they are more effective. For example, eserine in castor oil in the palliative treatment of chronic glaucoma, or homatropine in refraction work. Oily preparations are perhaps less used than they might be owing to their messiness. This arises from too much being put into the eye by using a glass

rod or dropper. The "pin" eye-dropper meets this difficulty. It is an ordinary domestic pin fixed into a suitable handle, and the whole chromium plated. If the head only of the pin be dipped into the oil it will lift a globule of the right volume, which by a touch on the mucosa of the lower lid is transferred to the eye. The dropper can be boiled. It is made by Messrs. W. Martindale, of New Cavendish Street, W.1.

\section{A BI-CYLINDRICAL TYPE READER}

BY

\author{
G. B. Lowe, D.O.(Oxon.) \\ BEXHILL-ON-SEA
}

INCREASING the height of a letter form is well known to increase legibility owing to the reading sight travelling along the top of the print. When the lower half of a line of print only is seen, the line can scarcely be read. 